\title{
Fertility and time inconsistency
}

\author{
Matthias Wrede* \\ RWTH Aachen University and CESifo \\ This version: January 2007
}

\begin{abstract}
This paper analyzes the impact of (quasi-) hyperbolic discounting on timing and numbers of births. Using a simple three period model it shows that without the ability to save and borrow hyperbolic discounters postpone births and give birth to less children than previously intended. In the presence of a (perfect) capital market additional qualifications are required to obtain similar results. In addition, a rough empirical cross country analysis using continued smoking as proxy for inconsistency shows that time inconsistency indeed reduces the number of births.
\end{abstract}

JEL classification: J13, D19, D91.

Keywords: Fertility, quasi-hyperbolic discounting, time inconsistency.

*Address: RWTH Aachen University, Department of Business and Economics, Templergraben 64, 52056 Aachen, Germany, email: mwr@fiwi.rwth-aachen.de. 


\section{Introduction}

Fertility-related behavior in developed countries has changed dramatically over the last thirty years. First, fertility rates declined sharply. The average total fertility rate in OECD countries fell from an average of 2.7 children per woman of childbearing age in 1970 to 1.6 in 2002 [d'Addio and d'Ercole (2005)]. Second, the first childbirth was postponed more and more. On average the mean age at first childbirth has increased from 23.8 in 1970 to 27.2 in 2000 [d'Addio and d'Ercole (2005)]. As a consequence, the number of families with four and more children has declined sharply over the period 1970-2000. Postponement increased the number of childless women and the number of women with less children than desired. Older women face higher risks of miscarriage and of chromosomal anomalies of infants.

The changes in fertility behavior have dramatic transitory and permanent effects on social security, tax revenue, public spending pattern, utilization of public infrastructure, average productivity and the society's potential to innovate. As a consequence, many countries have changed family policies to turn around this development.

A deep understanding of fertility behavior is necessary to shape family policy in the best possible way. The decline in the fertility rate could be explained with, on the one hand, the increasing cost of female time and with, on the other hand, the quantity-quality tradeoff combined with increasing incomes [see, among others, Becker and Lewis (1973)]. Social security also reduces fertility [for empirical evidence see Cigno and Rosati (1996) and Boldrin et al. (2005)], since pensions crowds out transfer schemes [Cigno (1993)] and, even if parents are altruistic toward their children, the implicit tax on contributions raises the price of a child, reducing the demand for children [Becker and Barro (1988)].

Postponement may have many causes. First, when women start with a high stock of capital which depreciates during the maternal leave, opportunity costs decline over the life cycle which in turn leads to postponement of first childbirth [Happel et al. (1984), Moffitt (1984)]. Since the fraction of women with tertiary education has increased over the last three decades, women do nowadays indeed start with a high stock of human capital. Furthermore, the lack of affordable high-quality child care institutions still forces mothers at least in some OECD countries to interrupt their working career [for an overview on the 
affordability of professional child care see Immervoll and Barber (2005)]. When earnings of the partner increase over the life cycle, marginal utility of income declines (at least if the capital market is perfectly imperfect) and opportunity costs of childbearing shrinks [Happel et al. (1984)]. Postponement of childbirth is also necessary if credit constraints force young women and couples to save in advance of childbirth [Hotz et al. (1997)]. Furthermore, the potenital for contraceptive failure may lead women to contracept early in her life cycles and thus to postpone first childbirth [Heckman and Willis (1975)]. In addition, women might overrate their individual fertility [Lampi (2006)]. Finally, the medical progress as such has increased the number of late childbirths (although the number of mothers older than 49 at time of birth is still low).

All the standard models of fertility assume perfectly rational actors, although many recent experimental studies have confirmed that bounded rationality is a widespread phenomenon. Many competing approaches are used to explain seemingly irrational behavior in a wide range of applications [see Bernheim and Rangel (2005) for a critical discussion of the implications for welfare economics]. Since giving birth to children has long-lasting consequences, theories of bounded rationality focussing on time discounting [for an overview see Frederick et al. (2002)] are appropriate to analyze fertility of women that are less than perfectly rational. There is a lot of experimental evidence that the discount rate declines with the time horizon [see, among others, Thaler (1981)]. Since it is well accepted that declining discount rate affect savings [see, e.g., Laibson (1997)], addiction [see Gruber and Köszegi (2002)] and the retirement decision [see Diamond and Köszegi (2003)], it is natural to analyze how declining discount rates affect fertility. As has been already discussed by Strotz (1956), non-exponential discounting raises the issue of time inconsistency, since at every moment previously optimal decisions become suboptimal after the change in the discount rate.

This paper intends to analyze whether declining discount rates have an effect on the total number of children as well as on the timing of childbirths. For the theoretical analysis, I rely on the concept of quasi-hyperbolic discounting introduced by Laibson (1997) which strongly simplifies the analysis of declining discount rates. A simple three period model is rich enough to generate effects of quasi-hyperbolic discounting on fertility. The main results are the following: First, it turns out that the characteristics of the capital market are 
important. Without access to the capital market, savings decisions and fertility behavior do not interact, leading to unambiguous effects of quasi-hyperbolic discounting on fertility behavior. Women whether naive or sophisticated postpone births as long as there are some benefits from children in the far future (e.g., if children support their old mother). Naive woman give birth to less children than intended. Second, access to a perfect capital market makes results ambiguous. If child care costs do not decline over the life cycle, rational and irrational women do not postpone births at all. Things change if opportunity costs of childbearing decline over time. Now it matters whether children are consumption goods or investment goods. Only if present benefits of children are sufficiently small compared to future benefits, women postpone births. Otherwise, immediate benefits of children induce quasi-hyperbolic discounters to bring births forward (since costs can be shifted in the future via the capital market). Under the circumstances, naive women bear less children than previously planned.

In an empirical cross country study with EU data, I use continued smoking as proxy for inconsistency, showing time inconsistency indeed reduces the number of births.

The paper is organized as follows. The next section develops the theoretical model and analyzes the impact of declining discount rates on timing and number of births when mothers can neither save nor borrow. Section three extends the analysis to woman's decisions with access to a perfect capital market. Section four presents the empirical analysis and section five concludes.

\section{Time inconsistent birth control and a perfectly im- perfect capital market}

In order to discuss the impact of quasi-hyperbolic discounting on fertility, I consider a woman who lives three periods but is fertile only in period one and two. Consumption and income in period $i$ are denoted by $c_{i}$ and $y_{i}$, respectively. In this section I assume that the income profile is exogenous and that the capital market is perfectly imperfect, i.e. the woman can neither save nor borrow. In period $i, i=1,2$, she chooses the number of children $n_{i}$, who involve child care costs $k_{i} n_{i}$ which cover opportunity costs of time, fees 
of day care centers, food, clothes, etc. For simplicity I treat the number of children as a continuous variable with $n_{i} \geq 0$. Consumption in period $i$ is a residual and given by $y_{i}-k_{i} n_{i}$.

The woman derives utility from consumption and children. In order to reduce ambiguity, I assume additive separability. Children increase utility as consumption goods when they are young, $w\left(n_{t}\right)$, and as investment goods when the mother is old, $v\left(n_{1}+n_{2}\right)$ (e.g., because the mother expects support from her children). Remaining-lifetime utility in period $s$ is

$$
U_{s}=\gamma\left[u\left(c_{s}\right)+w\left(n_{s}\right)\right]+\sum_{t=s+1}^{3} \delta^{t-s} u\left(c_{t}\right)+\sum_{t=s+1}^{2} \delta^{t-s} w\left(n_{t}\right)+\delta^{3-s} v\left(n_{1}+n_{2}\right) .
$$

The subutility functions $u(\cdot), v(\cdot)$, and $w(\cdot)$ are twice differentiable, increasing, and strictly concave. By $\delta$ the "normal" discount factor is indicated. If $\gamma$ were equal to one, preferences would be perfectly time consistent. A $\gamma>1$ captures quasi-hyperbolic discounting, since it decreases the utility of the future relative to the present. While from the point of view of period $s$ the marginal rate of substitution between consumption in period $s+1$ and consumption in period $s+2$ is $u^{\prime}\left(c_{s+1}\right) / \delta u^{\prime}\left(c_{s+2}\right)$, it increases to $\gamma u^{\prime}\left(c_{s+1}\right) / \delta u^{\prime}\left(c_{s+2}\right)$ in period $s+1$. I assume that the woman does not foresee this preference shift. As usual I call her therefore "naiv". In contrast to a naive agent, a sophisticated agent foresees her preference shift. A sophisticated mother would commit herself to the actually intended number of children if there were adequate instruments. For example, by sterilization she could hinder herself from giving birth to children. However, this extreme instrument would take away flexibility which she might want to have in an uncertain environment. Hence, I also consider briefly sophisticated women without access to a commitment technology.

In the first period, by choosing $n_{1}$ and making plans for $n_{2}$ the naive woman maximizes the utility function (1) for $s=1$. The first-order conditions (for interior solutions) for the number of children are:

$$
\begin{aligned}
& \gamma w^{\prime}\left(n_{1}\right)+\delta^{2} v^{\prime}\left(n_{1}+n_{2}\right)-\gamma k_{1} u^{\prime}\left(c_{1}\right)=0, \\
& \delta w^{\prime}\left(n_{2}\right)+\delta^{2} v^{\prime}\left(n_{1}+n_{2}\right)-\delta k_{2} u^{\prime}\left(c_{2}\right)=0 .
\end{aligned}
$$

When child care costs and/or income change over time, a corner solution especially for one period cannot be excluded. However, if income and costs vary not too much (or in opposite 
directions), births in both periods are a likely outcome of the optimization problem. As will be discussed later in detail, with perfect capital markets the mother will shift income intertemporally and will not give birth to children in the first period when consumption benefits $w(\cdot)$ do not arise.

In the second period the mother reconsiders her plans for this period. By choosing $n_{2}$ she maximizes the utility function (1) for $s=2$. The first-order condition (for an interior solution) is:

$$
\gamma w^{\prime}\left(n_{2}\right)+\delta v^{\prime}\left(n_{1}+n_{2}\right)-\gamma k_{2} u^{\prime}\left(c_{2}\right)=0 .
$$

Since this condition differs from (3), she deviates from her previous plans.

In the third period there is no decision left and the mother consumes her entire income (since a bequest motive is excluded by assumption).

In order to analyze the impact of quasi-hyperbolic discounting on births, I consider the impact of a small increase in the preference parameter $\gamma$ (for calculations see the appendix). In the first period an increase in $\gamma$ yields:

$$
\frac{\partial n_{1}}{\partial \gamma}<0 \quad \text { and } \quad \frac{\partial n_{2}}{\partial \gamma}>0
$$

When the present becomes more valuable, the woman tries to shift a part of the burden of motherhood into the future. This holds true as long as some benefit of motherhood is delayed and is felt only in the last period. Without an investment effect of motherhood, i.e. if $v(\cdot) \equiv 0$, a change in $\gamma$ leaves birth control unaltered.

In the second period the number of births changes according to:

$$
\frac{\partial n_{2}}{\partial \gamma}<0 \text { and } \frac{\partial n_{2}}{\partial n_{1}}<0
$$

Again, investment in children is less attractive when the future is (implicitly) discounted more heavily. Hence, the mother reduces the number of births in reaction to an increase in $\gamma$. This reaction was not intended in the first period. Furthermore, the mother would give birth to more children in the second period in reaction to a decrease in the number of births in the first period, since an additional child is more valuable as an investment when the number of children is small. At $\gamma=1$ this combined effect $\left(\partial n_{2} / \partial n_{1}\right)\left(\partial n_{1} / \partial \gamma\right)$ 
exactly coincides with the first period plans $\partial n_{2} / \partial \gamma$. The sign of the true total effect on the number of births in the second period

$$
\frac{\partial n_{2}}{\partial n_{1}} \frac{\partial n_{1}}{\partial \gamma}+\frac{\partial n_{2}}{\partial \gamma}
$$

is ambiguous. The following proposition summarizes the results:

Proposition 1 Introducing quasi-hyperbolic preferences on a perfectly imperfect capital market leads to postponement of births and to less children in the second period than intended.

The first order condition for a sophisticated mother, who chooses $n_{1}$ as to maximize the utility function (1) for $s=1$ subject to $n_{2}=n_{2}\left(n_{1}\right)$, where $n_{2}$ is calculated from the solution of the second period problem, is

$$
\begin{gathered}
\gamma w^{\prime}\left(n_{1}\right)+\delta^{2} v^{\prime}\left(n_{1}+n_{2}\right)-\gamma k_{1} u^{\prime}\left(c_{1}\right) \\
+\left[\delta w^{\prime}\left(n_{2}\right)+\delta^{2} v^{\prime}\left(n_{1}+n_{2}\right)-\delta k_{2} u^{\prime}\left(c_{2}\right)\right] \frac{\partial n_{2}}{\partial n_{1}}=0 .
\end{gathered}
$$

From the previous analysis follows that the second row is negative, since the term in square brackets is unambiguously positive for $\gamma>1$ (since from second period optimization follows that the respective term with a $\gamma$ attached to second period marginal benefits is zero). The sophisticated mother has an additional incentive to postpone births in order to encourage her second period "self" to give birth to more children. The following proposition restates this result:

Proposition 2 Sophisticated women with quasi-hyperbolic preferences postpone births even more than naive women.

\section{Time inconsistent birth control and a perfect capi- tal market}

In contrast to the previous section, I assume that the woman under consideration has unrestricted access to a perfect capital market where the interest rate is $r$. Savings in 
period $i$ are denoted $s_{i}$. She is endowed with $\omega$ and has (for simplicity) no other income. Hence, $y_{1}=\omega$ and $y_{j}=(1+r) s_{j-1}, j=2,3$. In the presence of a perfectly capital market an assumption concerning the time profile of child care costs is necessary to obtain clearcut results. Happel et al. (1984) have shown that opportunity costs of motherhood shrink over time when women are well educated and human capital depreciates during a maternal leave. Therefore, I assume that child care costs at least do not increase too much over time: $k_{2} /(1+r)<k_{1}$. Since the woman has access to a capital market, an intertemporal budget constraint can be constructed for any period $s$ which is

$$
y_{s} \geq \sum_{t=s}^{3} \frac{c_{t}}{(1+r)^{t-s}}+\sum_{t=s}^{2} \frac{k_{t} n_{t}}{(1+r)^{t-s}} .
$$

In the first period by choosing $c_{1}$ and $n_{1}$ and making plans for $c_{2}, n_{2}$, and $c_{3}$ the naive woman maximizes the utility function (1) for $s=1$ subject to the budget constraint (9) (for $s=1$ ). Solving (9) for $c_{3}$ and inserting into (1) the first-order conditions for consumption are: ${ }^{1}$

$$
\begin{aligned}
\gamma u^{\prime}\left(c_{1}\right)-\delta^{2}(1+r)^{2} u^{\prime}\left(c_{3}\right) & =0 \\
u^{\prime}\left(c_{2}\right)-\delta(1+r) u^{\prime}\left(c_{3}\right) & =0 .
\end{aligned}
$$

The marginal rate of substitution between consumption in period $i$ and consumption in period $i+1$ should be equal to $1+r, i=1,2$. The first-order conditions for the number of children are:

$$
\begin{aligned}
\gamma w^{\prime}\left(n_{1}\right)+\delta^{2} v^{\prime}\left(n_{1}+n_{2}\right)-\delta^{2}(1+r)^{2} k_{1} u^{\prime}\left(c_{3}\right) & \leq 0 \\
\delta w^{\prime}\left(n_{2}\right)+\delta^{2} v^{\prime}\left(n_{1}+n_{2}\right)-\delta^{2}(1+r) k_{2} u^{\prime}\left(c_{3}\right) & \leq 0
\end{aligned}
$$

where "=" holds if the woman decides to give birth to children in the respective period. The sum of the marginal consumption and investment benefit of children should be not larger than marginal utility loss due to (opportunity) costs of children.

In period 2 the woman reconsiders her decisions with respect to the number of children and consumption in this period. Through the choice of $c_{2}$ and $n_{2}$, she maximizes for $s=2$

\footnotetext{
${ }^{1}$ I assume throughout the paper that strictly positive consumption is optimal in any period.
} 
the utility function (1) after inserting for $c_{3}$ according to the budget constraint (9) for $s=2$. First-order conditions (for interior solutions) are:

$$
\begin{aligned}
\gamma u^{\prime}\left(c_{2}\right)-\delta(1+r) u^{\prime}\left(c_{3}\right) & =0, \\
\gamma w^{\prime}\left(n_{2}\right)+\delta v^{\prime}\left(n_{1}+n_{2}\right)-\delta(1+r) k_{2} u^{\prime}\left(c_{3}\right) & =0 .
\end{aligned}
$$

Since her preferences for immediate payoffs in this period are stronger now, she makes her choices not perfectly according to her previous intentions. How quasi-hyperbolic preferences affect the number and the timing of births depends crucially on how they affect utility in the presence of a perfect capital market. Since general results are ambiguous, I analyze the extreme cases "pure investment utility" and "pure consumption utility".

\subsection{Pure investment benefit}

If children provide no consumption utility, i.e. if $w(\cdot) \equiv 0$, women postpone births until period 2. Since for all $n_{1}$ and $n_{2}$ the LHS of (13) is larger than the LHS of (12), $n_{1}=0$ is certainly optimal. This holds true for women with consistent preferences and for naive women with quasi-hyperbolic discounting and is purely driven by decreasing opportunity costs of children. A small increase in the preference parameter $\gamma$ leads to:

$$
\frac{\partial n_{2}}{\partial s_{1}} \frac{\partial s_{1}}{\partial \gamma}+\frac{\partial n_{2}}{\partial \gamma}<0
$$

First of all, the higher preference for the present time increases consumption in the first period and reduces savings $s_{1}=\omega-c_{1}$. This in turn reduces income in the second period and, therefore, increases marginal utility of income in the second period. Children become more expensive. The woman reduces the number of births in the second period. Qualitatively, this effect could also be observed, if the woman already decided in the first period definitly on the number of births in the second period. At $\gamma=1$ the reaction to lower savings in the second period is exactly the same as the reaction would have been in the first period. However, while this effect could be considered as an intended reaction, there is also a second not-intended effect. When $\gamma$ is raised, second period consumption is more valuable and the woman gives birth to less children than planned in the first period. Hence, quasi-hyperbolic preferences cause time inconsistent birth control. Both 
the intended and the unintended effect of an increase in $\gamma$ are negative. Quasi-hyperbolic preferences lead to less children. The following proposition summarizes the main result:

Proposition 3 Introducing quasi-hyperbolic preferences on a perfect capital market leads to less children than intended when the mother only benefits from children when she is old.

Since the number of children is smaller than previously planned, there is also an excess endowment in the second period (compared to plans).

\subsection{Pure consumption benefit}

If children provide no investment utility, i.e. if $v(\cdot) \equiv 0$, women give usually birth to children in both periods. Although without additional assumptions on $w(\cdot)$ corner solutions are in principle possible, I focus on interior solutions. If the woman intends to give birth to children in both periods, she chooses $n_{1}$ and intends to choose $n_{2}$ as to equalize the ratio of present values of marginal consumption benefits of children with the ratio of marginal costs:

$$
\frac{\gamma w^{\prime}\left(n_{1}\right)}{\delta w^{\prime}\left(n_{2}\right)}=\frac{(1+r) k_{1}}{k_{2}}
$$

This holds true independent of whether she is perfectly rational or naive. With consumption benefits a higher $\gamma$ gives incentive to increase births and consumption in the first period:

$$
\frac{d n_{1}}{d \gamma}>0 \quad \text { and } \quad \frac{d c_{1}}{d \gamma}>0
$$

Since the woman feels the benefits of children immediately, she wants to have more children right now. Since higher child care costs and higher first period consumption reduce savings, second period income is reduced. Due to the higher marginal utility of income in the second period, she gives birth to less children in the second period:

$$
\frac{\partial n_{2}}{\partial s_{1}} \frac{\partial s_{1}}{\partial \gamma}<0
$$

A general reduction in the rate of time preference would have similar effects. However, there is again an unintend impact on births in the second period:

$$
\frac{\partial n_{2}}{\partial \gamma}>0
$$


Since in the second period consumption utility of children is more valuable than expected, the woman gives birth to more children than previously intended for this period. The following proposition states this result again:

Proposition 4 Introducing quasi-hyperbolic preferences on a perfect capital market leads to more children than intended in the second period when the mother only benefits from children while they are young.

Whether an increase in $\gamma$ altogether increases the number of children in period 2 and in both periods together is not entirely clear.

\subsection{Sophisticated mother}

Sophisticated mothers foresee the preference shift and try to face it. In the analysis of sophisticated behavior I assume that the number of births in the second period is strictly positive. In the first period by choosing $c_{1}$ and $n_{1}$ she maximizes the utility function (1) for $s=1$, where $c_{3}$ is substituted according to the budget constraint (9) (for $s=1$ ), subject to $n_{2}=n_{2}\left(c_{1}, n_{1}\right)$ and $c_{2}=c_{2}\left(c_{1}, n_{1}\right) . n_{2}$ and $c_{2}$ are calculated from the solutions of the second period problem. First-order conditions are

$$
\begin{aligned}
\gamma u^{\prime}\left(c_{1}\right) & -\delta^{2}(1+r)^{2} u^{\prime}\left(c_{3}\right)+\left[\delta u^{\prime}\left(c_{2}\right)-\delta^{2}(1+r) u^{\prime}\left(c_{3}\right)\right] \frac{\partial c_{2}}{\partial c_{1}} \\
+ & {\left[\delta w^{\prime}\left(n_{2}\right)+\delta^{2} v^{\prime}\left(n_{1}+n_{2}\right)-\delta^{2}(1+r) k_{2} u^{\prime}\left(c_{3}\right)\right] \frac{\partial n_{2}}{\partial c_{1}}=0 } \\
\gamma w^{\prime}\left(n_{1}\right)+\delta^{2} v^{\prime}\left(n_{1}+n_{2}\right)- & \delta^{2}(1+r)^{2} k_{1} u^{\prime}\left(c_{3}\right)+\left[\delta u^{\prime}\left(c_{2}\right)-\delta^{2}(1+r) u^{\prime}\left(c_{3}\right)\right] \frac{\partial c_{2}}{\partial n_{1}} \\
+ & {\left[\delta w^{\prime}\left(n_{2}\right)+\delta^{2} v^{\prime}\left(n_{1}+n_{2}\right)-\delta^{2}(1+r) k_{2} u^{\prime}\left(c_{3}\right)\right] \frac{\partial n_{2}}{\partial n_{1}} \leq 0 }
\end{aligned}
$$

From second period behavior it is obvious that

$$
\frac{\partial c_{2}}{\partial c_{1}}<0, \quad \frac{\partial n_{2}}{\partial c_{1}}<0, \quad \text { and } \quad \frac{\partial c_{2}}{\partial n_{1}}<0
$$

Higher first period consumption reduces the endowment in the second period which unambiguously decreases consumption and the number of children. A higher number of births also reduces unambiguously via the same channel second period consumption. However, the impact of a change in the number of births in the first period on second period births 
is in general ambiguous, since first-period births affect savings and old-age benefits of children. Without old-age benefits only the savings channel remains, and $\partial n_{2} / \partial n_{1}<0$. The terms in square brackets are all negative for $\gamma>1$ (since from second period optimization follows that the respective terms with a $\gamma$ attached to second period marginal benefits are zero). Hence, a woman who realizes the preference shift is - compared too the naive type - encouraged to increase first period consumption in order to reduce the second period endowment, since she does not agree with her second period "self" on the allocation of resources. In the absence of consumption benefit of children, she has also an additional incentive to give birth to children in the first period. However, when opportunity costs decline sharply over the life cycle, this incentive may be to small to induce motherhood in the first period. If immediate benefits of children are prevalent, a sophisticated woman may even reduce the number of births in the first period. The following proposition summarizes the result:

Proposition 5 A sophisticated woman consumes more in the first period than a naive woman. If opportunity costs decline sufficiently sharp over the life cycle, even sophisticated woman postpone births.

\subsection{Extensions}

I will briefly discuss some possible extensions:

First, if child care costs increased over time, any rational or naive woman without a consumption motive of motherhood would give birth to children only in the first period, since a delay would increase life time costs of children. Given a strong motive for early births declining discount factors do not affect the timing of childbirth.

Second, a wider time horizon per se does not change the main results qualitatively. With declining child care costs, in the absence of a children consumption motive women would give birth only in the last period where they are fertile and a naive woman would have less children than previously intended.

Third, opportunity costs of motherhood which are u-shaped over time would push motherhood to the minimum of child care costs (when a children consumption motive is 
still absent). Even naive woman would act like that (with less children than planned in earlier stages of life).

\section{Empirical model}

Although a perfect capital market requires a more differentiated view, the bottom line of the theoretical model is that quasi-hyperbolic discounting women postpone births and reduce the number of children. In this section I demonstrate rough empirical tests of these hypotheses. More precisely, I test whether time inconsistency reduces births. Since time inconsistency cannot be tested directly and due to a lack of simultaneous individual data on discounting rates and fertility, I use aggregate data of the European Union in 2005 (or the most recent data available) and a proxy for inconsistency. ${ }^{2}$ I measure fertility alternatively by the total fertility rate [fertility], i.e. the sum of age specific fertility rates of women between 15 and 49 divided by 1000, and the crude birth rate [birthrate], i.e. the number of births p.a. divided by 1000 inhabitants. As proxy for inconsistency I take the number of actual smokers divided by the sum of actual and former smokers [ctsmoke]. This variable does not measure the prevalence of smoking per se, which is influenced by income, unemployment, the public attitude to smoking etc. It grasps the readiness and the ability of smokers to quit smoking. Since health risks of long-standing smoking are well known in developed countries, time consistent agents should either not start smoking at all or quit smoking after a while. Naive agents overestimate their ability to stop smoking when they smoke their first cigarette. Gruber and Köszegi (2002) have based their analysis of tobacco taxes on the assumption that smokers are quasi-hyperbolic discounters. The identifying assumption in the following analysis is that the ratio of continued smokers is higher if the fraction of naive agents is higher.

Figure 1 suggests that there is indeed a negative relationship between the proxy for inconsistency and the fertility rate (in logarithms). An OLS cross country analysis confirms this impression not only for the fertility rate,

$$
\ln (\text { fertility })_{i}=\beta_{0}+\beta_{1} \text { ctsmoke }_{i}+\sum_{j} \beta_{j} \operatorname{control}_{j i}+\epsilon_{i}
$$

\footnotetext{
${ }^{2}$ For a more detailed description of the data and the sources see the appendix.
} 


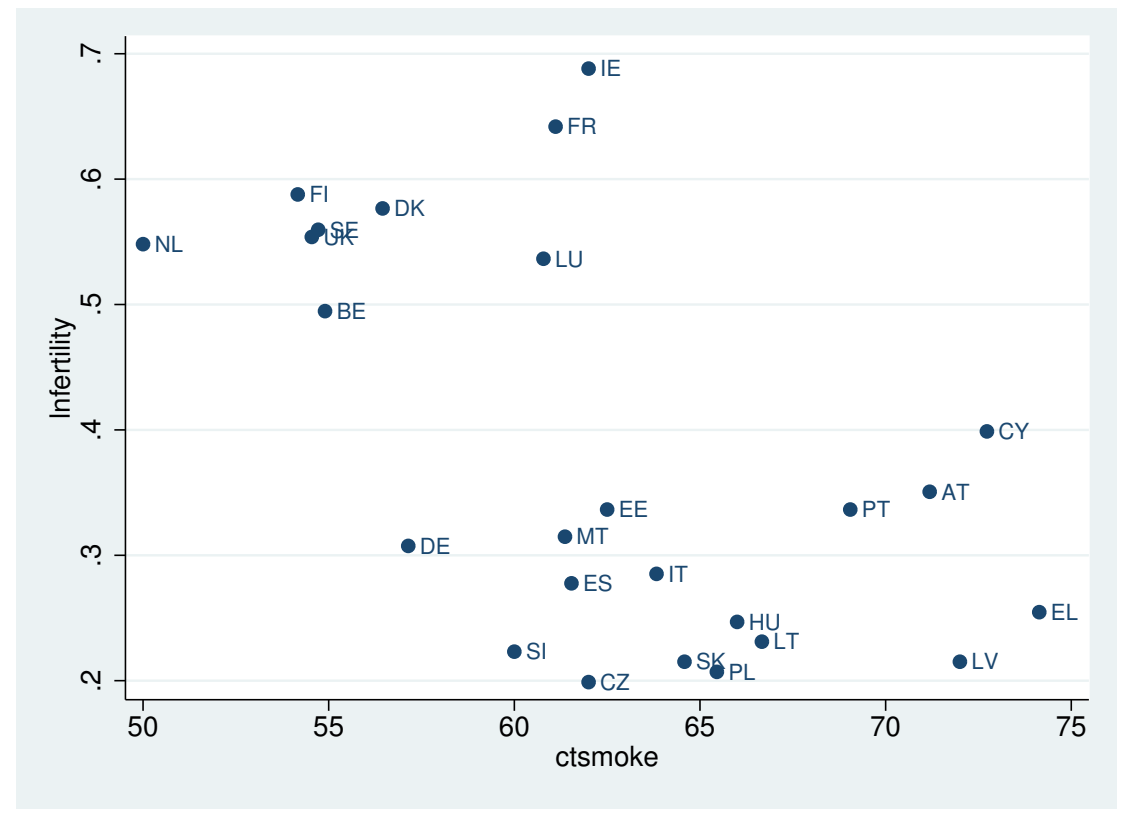

Figure 1: Smoking and fertility

but also for the crude birth rate [see table 1]. Control variables are public expenditure on family and children $\%$ of GDP [childexp], the female long term unemployment ratio [ltunemp] and, in the estimation of the crude birth rate, the median age [medianage]. All coefficients including those of the control variables have the expected signs, most effects are also statistically significant.

Since it is quite reasonable to argue that even continued smoking is not exogenous, but endogenously and simultaneously determined with birth control, I also estimate the relationship of continued smoking and birth control with 2SLS (although a Durbin-WuHausman test does not reject exogeneity). Since a closer inspection of health risk perception and smoking behavior reveals that the ratio of continued smokers strongly declines with the perception of serious health risks (for non-smokers) [see figure 2], I used as instruments for continued smoking the fraction of citizens who expects that smoking causes for non smokers some health problems such as respiratory problems [healthprob] and the fraction of citizens who think that smoking causes for non smokers serious illness as cancer [cancer]. In addition I used the retail price per pack of 20 cigarettes of the most popular price category divided by the GDP per capita [relprice]. The identifying assumption, namely that these instruments have no direct impact on birth control, is confirmed by an overidentification- 


\begin{tabular}{|c|c|c|c|c|}
\hline & $\begin{array}{c}\text { OLS } \\
\ln (\text { fertility })\end{array}$ & $\begin{array}{c}\text { OLS } \\
\ln \text { (birthrate) }\end{array}$ & $\begin{array}{c}\text { 2SLS } \\
\ln (\text { fertility })\end{array}$ & $\begin{array}{c}\text { 2SLS } \\
\ln \text { (birthrate) }\end{array}$ \\
\hline \multirow[t]{2}{*}{ ctsmoke } & $-0.893^{* *}$ & $-0.820^{* *}$ & $-1.185^{* *}$ & -0.732 \\
\hline & $(-2.41)$ & $(-2.50)$ & $(-2.22)$ & $(-1.58)$ \\
\hline \multirow[t]{2}{*}{ childexp } & $4.946^{*}$ & 3.012 & $4.594^{*}$ & 3.093 \\
\hline & $(2.02)$ & $(1.40)$ & $(1.82)$ & $(1.42)$ \\
\hline \multirow[t]{2}{*}{ ltunemp } & $-0.0187^{* *}$ & $-0.0160^{* *}$ & $-0.0172^{*}$ & $-0.0164^{* *}$ \\
\hline & $(-2.30)$ & $(-2.26)$ & $(-2.02)$ & $(-2.26)$ \\
\hline \multirow[t]{2}{*}{ medianage } & & $-0.0409^{* * *}$ & & $-0.0403^{* * *}$ \\
\hline & & $(-3.97)$ & & $(-3.82)$ \\
\hline \multirow[t]{2}{*}{ Constant } & $0.911^{* * *}$ & $4.449^{* * *}$ & $1.095^{* * *}$ & $4.372^{* * *}$ \\
\hline & $(3.74)$ & $(9.17)$ & $(3.19)$ & $(7.74)$ \\
\hline$R^{2}$ & 0.60 & 0.62 & 0.59 & 0.61 \\
\hline Overidentification & - & - & 0.7445 & 0.8802 \\
\hline
\end{tabular}

Table 1: OLS and 2SLS estimation of the number of births

test. On the whole, the 2SLS analysis confirms the OLS results. The ratio of continued smokers decreases the fertility rate and the crude birth rate. Continued smoking and giving birth to children are substitutes.

The empirical analysis is only a first and rough trial to test the hypotheses of the theoretical model. There are several shortcomings: First, although I tried to control for endogeneity and simultaneity, this might be considered as an unsolved problem. Although I can make statements on the substitutability between continued smoking and fertility, at the end of the day I was not able to perfectly isolate inconsistency. Coefficients might be considered as biased estimators of inconsistency. Second, there might exist a strong link between continued smoking and births. An expectant mother has a stronger incentive to quit smoking because of the health risk for the child. Third, via biochemical channels smoking might also directly reduce the ability to give birth to children. Fourth, a simple cross section analysis lacks the opportunity to control for unobserved heterogeneity. Fifth, the underlying structure of decisions on timing of births is inherent dynamic, which could 


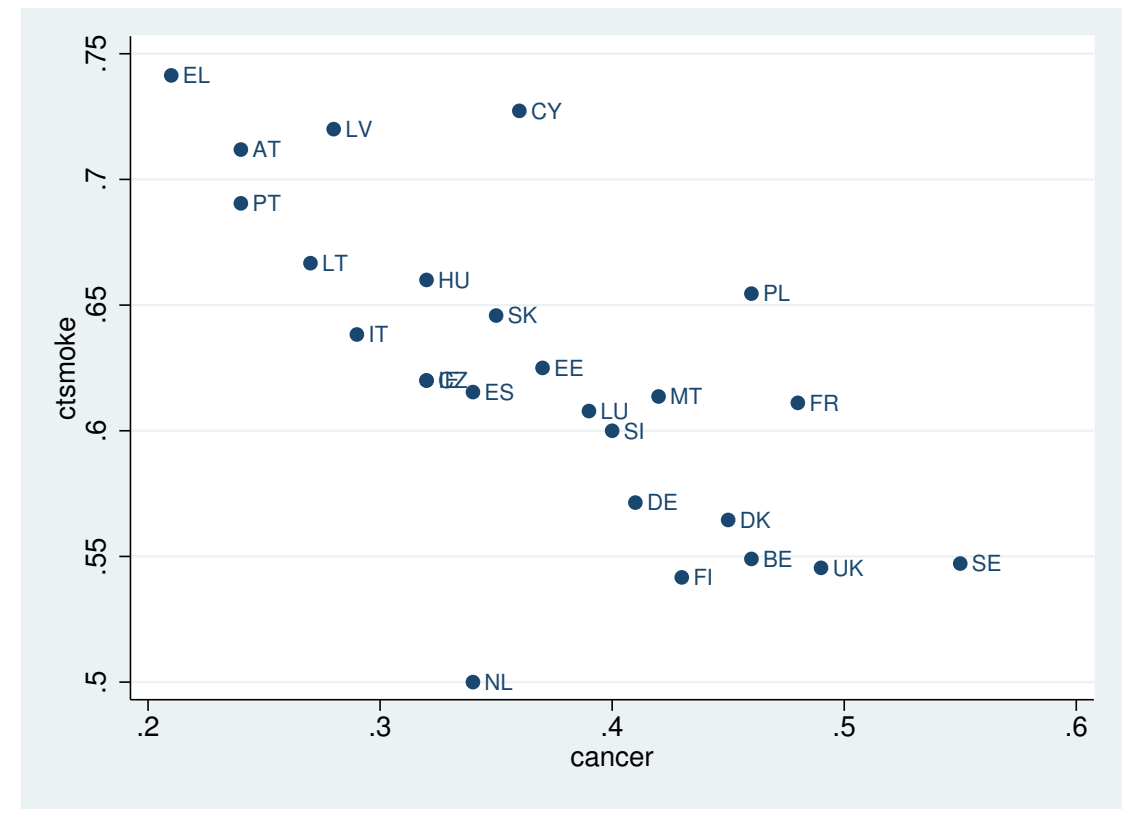

Figure 2: Assessment of health risk and smoking

not be taken into account in a static analysis. However, due to the dynamic nature of the decision problem it is quite complicated to specify a panel model correctly.

\section{Concluding remarks}

This paper analyzed the impact of (quasi-) hyperbolic discounting on timing and numbers of births. With a simple three period model it has shown that without the ability to save and borrow naive hyperbolic discounters postpone births and give birth to less children than previously intended. Even sophisticated mothers postpone births. In the presence of a (perfect) capital market additional qualifications are required to end up with similar results. Hyperbolic discounting reduces the number of births relative to intentions if opportunity costs of children decline over the life cycle and the investment motive of motherhood is prevalent. Otherwise, declining discount rates may have an opposite effect of births. The paper also showed with a rough empirical cross country analysis using continued smoking as proxy for inconsistency that time inconsistency reduces the number of births. 


\section{Appendix}

\section{A perfectly imperfect capital market}

Totally differentiating the first-order conditions in the first period (2) and (3) leads to ${ }^{3}$ :

$$
\begin{aligned}
\frac{\partial n_{1}}{\partial \gamma} & =\frac{\left[k_{1} u_{1}^{\prime}-w_{1}^{\prime}\right]\left[\delta w_{2}^{\prime \prime}+\delta^{2} v^{\prime \prime}+\delta k_{2}^{2} u_{2}^{\prime \prime}\right]}{\Delta_{1}}<0, \\
\frac{\partial n_{2}}{\partial \gamma} & =\frac{\delta^{2} v^{\prime \prime}\left[w_{1}^{\prime}-k_{1} u_{1}^{\prime}\right]}{\Delta_{1}}>0,
\end{aligned}
$$

where

$$
\Delta_{1}=\gamma \delta^{2} v^{\prime \prime}\left[k_{1} u_{1}^{\prime \prime}+k_{2} u_{2}^{\prime \prime}\right]+\delta w_{2}^{\prime \prime}\left[\delta^{2} v^{\prime \prime}+\gamma k_{1}^{2} u_{1}^{\prime \prime}\right]+\gamma w_{1}^{\prime \prime}\left[\delta^{2} v^{\prime \prime}+\delta k_{2}^{2} u_{2}^{\prime \prime}\right]+\gamma \delta w_{1}^{\prime \prime} w_{2}^{\prime \prime}>0
$$

Totally differentiating the first-order conditions in the second period (4) yields

$$
\begin{aligned}
\frac{\partial n_{2}}{\partial \gamma} & =\frac{k_{2} u_{2}^{\prime}-w_{2}^{\prime}}{\gamma w_{2}^{\prime \prime}+\delta v^{\prime \prime}+\gamma k_{2} u_{2}^{\prime \prime}}<0, \\
\frac{\partial n_{2}}{\partial n_{1}} & =-\frac{\delta v^{\prime \prime}}{\gamma w_{2}^{\prime \prime}+\delta v^{\prime \prime}+\gamma k_{2} u_{2}^{\prime \prime}}<0 .
\end{aligned}
$$

\section{Pure investment benefit with a perfect capital market}

If $w(\cdot) \equiv 0$, there are only investment benefits of children. Totally differentiating the first-order conditions in the first period (10), (11), and (13) as equality leads to

$$
\begin{aligned}
\frac{\partial c_{1}}{\partial \gamma} & =-\frac{\delta u_{1}^{\prime}\left\{u_{2}^{\prime \prime} v^{\prime \prime}+u_{3}^{\prime \prime}(1+r)^{2}\left[\delta v^{\prime \prime}+k_{2}^{2} u_{2}^{\prime \prime}\right]\right\}}{\Delta_{2}}>0, \\
\frac{\partial n_{2}}{\partial \gamma} & =\frac{\delta u_{1}^{\prime} u_{2}^{\prime \prime} u_{3}^{\prime \prime} k_{2}(1+r)^{3}}{\Delta_{2}}<0,
\end{aligned}
$$

where

$$
\Delta_{2}=\delta\left\{u_{1}^{\prime \prime} u_{3}^{\prime \prime} v^{\prime \prime} \delta \gamma(1+r)^{2}+u_{2}^{\prime \prime} u_{1}^{\prime \prime} v^{\prime \prime} \gamma+u_{2}^{\prime \prime} u_{3}^{\prime \prime}\left[v^{\prime \prime} \delta^{2}(1+r)^{4}+u_{1}^{\prime \prime} \gamma k_{2}^{2}(1+r)^{2}\right]\right\}<0 .
$$

Totally differentiating the first-order conditions in the second period (14) yields

$$
\begin{aligned}
& \frac{\partial n_{2}}{\partial c_{1}}=-\frac{u_{2}^{\prime \prime} u_{3}^{\prime \prime} \delta \gamma k_{2}(1+r)^{3}}{\Delta_{3}}<0, \\
& \frac{\partial n_{2}}{\partial \gamma}=\frac{u_{3}^{\prime \prime} \delta u_{2}^{\prime} k_{2}(1+r)^{2}}{\Delta_{3}}<0,
\end{aligned}
$$

\footnotetext{
${ }^{3}$ In the appendix a subscript indicates the period.
} 
where

$$
\Delta_{3}=\delta\left\{u_{2}^{\prime \prime} v^{\prime \prime} \gamma+u_{3}^{\prime \prime}(1+r)^{2}\left[v^{\prime \prime} \delta+u_{2}^{\prime \prime} \gamma k_{2}^{2}\right]\right\}>0
$$

Taking the actual decisions on $n_{2}$ in the second period and $c_{1}$ in first period into account, leads to

$$
\frac{\partial n_{2}}{\partial c_{1}} \frac{\partial c_{1}}{\partial \gamma}+\frac{\partial n_{2}}{\partial \gamma}<0
$$

where the total indirect effect $\left(\partial n_{2} / \partial c_{1}\right)\left(\partial c_{1} / \partial \gamma\right)$ is the same as the perceived direct effect $\partial n_{2} / \partial \gamma$ in the first period at $\gamma=1$.

\section{Pure consumption benefit with a perfect capital market}

If $v(\cdot) \equiv 0$, there are only consumption benefits of children. Totally differentiating the first-order conditions in the first period (10), (11), (12) and (13) and summarizing leads to

$$
\begin{aligned}
\frac{\partial s_{1}}{\partial \gamma} & =\frac{\gamma u_{1}^{\prime}\left(w_{1}^{\prime \prime}+u_{1}^{\prime \prime} k_{1}^{2}\right)\left\{u_{2}^{\prime \prime} w_{2}^{\prime \prime}+u_{3}^{\prime \prime} \delta(1+r)^{2}\left[w_{2}^{\prime \prime}+u_{2}^{\prime \prime} k_{2}^{2}\right]\right\}}{\Delta_{4}}<0, \\
\frac{\partial n_{1}}{\partial \gamma} & =-\frac{\gamma u_{1}^{\prime} u_{1}^{\prime \prime} k_{1}\left\{u_{2}^{\prime \prime} w_{2}^{\prime \prime}+u_{3}^{\prime \prime} \delta(1+r)^{2}\left[w_{2}^{\prime \prime}+u_{2}^{\prime \prime} k_{2}^{2}\right]\right\}}{\Delta_{4}}>0 \\
\frac{\partial n_{2}}{\partial \gamma} & =\frac{\gamma u_{2}^{\prime \prime} u_{3}^{\prime \prime} \delta u_{1}^{\prime} k_{2}\left(w_{1}^{\prime \prime}+u_{1}^{\prime \prime} k_{1}^{2}\right)(1+r)^{2}}{\Delta_{4}}<0
\end{aligned}
$$

where

$$
\begin{gathered}
\Delta_{4}=\gamma\left\{u_{1}^{\prime \prime} u_{3}^{\prime \prime} w_{1}^{\prime \prime} w_{2}^{\prime \prime} \delta \gamma(1+r)^{2}+u_{2}^{\prime \prime}\left[u_{1}^{\prime \prime} w_{1}^{\prime \prime} w_{2}^{\prime \prime} \gamma+u_{3}^{\prime \prime} \delta\left(u_{1}^{\prime \prime} w_{2}^{\prime \prime} \delta k_{1}^{2}(1+r)^{4}\right.\right.\right. \\
\left.\left.\left.+w_{1}^{\prime \prime}\left(w_{2}^{\prime \prime} \delta(1+r)^{4}+u_{1}^{\prime \prime} \gamma k_{2}^{2}(1+r)^{2}\right)\right)\right]\right\}>0 .
\end{gathered}
$$

Totally differentiating the first-order conditions in the second period (14) yields

$$
\begin{aligned}
& \frac{\partial n_{2}}{\partial s_{1}}=\frac{\gamma u_{2}^{\prime \prime} u_{3}^{\prime \prime} \delta k_{2}(1+r)^{3}}{\Delta_{5}}>0, \\
& \frac{\partial n_{2}}{\partial \gamma}=-\frac{\gamma u_{2}^{\prime} u_{2}^{\prime \prime} k_{2}}{\Delta_{5}}>0,
\end{aligned}
$$

where

$$
\Delta_{5}=\gamma\left\{u_{2}^{\prime \prime} w_{2}^{\prime \prime} \gamma+u_{3}^{\prime \prime} \delta(1+r)^{2}\left[w_{2}^{\prime \prime}+u_{2}^{\prime \prime} k_{2}^{2}\right]\right\}>0
$$




\section{Variables and sources}

\begin{tabular}{l|lll} 
Variable & Description & Year & Source \\
\hline fertility & fertility rate & 2004 & Eurostat \\
birthrate & crude birth rate & 2004 & Statistisches Bundesamt \\
medianage & median age & 2005 & UN \\
childexp & Public expenditure on family & 2003 & Eurostat \\
& and children \% of GDP & & \\
gdppc & GDP per capita & 2005 & Statistisches Bundesamt \\
ltunemp & female long term unemployment ratio & 2005 & Eurostat \\
neversmoked & you have never smoked (m+f) & 2005 & Eurobarometer special \\
stoppedsmoke & you stopped smoking (m+f) & 2005 & Eurobarometer special \\
cancer & Do you think, for the non-smoker, & 2005 & Eurobarometer special \\
& other people's smoke can & & \\
& even in the long term, cause & & \\
& serious illness such as cancer & & \\
healthprob & $\ldots$ cause some health problems & 2005 & Eurobarometer special \\
& such as respiratory problems & & \\
\hline & retail price of 20 cigarettes (MPPC) & 2006 & Cnossen (2006) \\
\hline
\end{tabular}

\section{References}

Becker GS and Barro RJ (1988). A reformulation of the economic theory of fertility. Quarterly Journal of Economics 103. 1-25.

Becker $\mathrm{G}$ and Lewis HG (1973). On the interaction between quantity and quality of children. Journal of Political Economy 81. S279-S288.

Bernheim BD and Rangel A (2005). Behavioral public economics: welfare and policy analysis with non-standard decision makers. NBER Working Paper 11518.

Boldrin M, De Nardi M and Jones LE (2005). Fertility and social security. NBER Working Paper 11146. 
Cigno A (1993). Intergenerational transfers without altruism. Family, market and state. European Journal of Political Economy 9. 505-518.

Cigno A and Rosati FC (1996). Jointly determined saving and fertility behaviour: theory, and estimates for Germany, Italy, UK and USA. European Economic Review 40. 15611589.

Cnossen S (2006). Tobacco taxation in the European Union. FinanzArchiv 62. 305-322.

d'Addio AC and d'Ercole MM (2005). Trend and determinants of fertility rates: the role of policies. OECD Social Employment and Migration Working Papers 27.

Diamond P and Köszegi B (2003). Quasi-hyperbolic discounting and retirement. Journal of Public Economics 87. 1839-1872.

Frederick S, Loewenstein G and O' Donoghue T (2002). Time discounting and time preference: a critical review. Journal of Economic Literature 40. 350-401.

Gruber J and Köszegi B (2002). A theory of government regulation of addictive bads: optimal tax levies and tax incidence for cigarette excise taxation. NBER Working Paper 8777.

Happel SK, Hill JK and Low SA (1984). An economic analysis of the timing of childbirth. Population Studies 38. 299-311.

Heckman J and Willis R (1975). Estimation of a stochastic model of reproduction: an econometric approach. In: N Terleckij (Ed.). Household production and consumption. Columbia University Press.

Hotz VJ, Klerman JA and Willis RJ (1997). The economics of ferility in developd countries. In: MR Rosenzweig and O Stark (Eds.). Handbook of population and family economics. Elsevier Science. 275-347.

Immervoll H and Barber D (2005). Can Parents afford to work? Cildcare costs, tax-benefit policies and work incentives. OECD Social Employment and Migration Working Papers 31. 
Laibson D (1997). Golden eggs and hyperbolic discounting. Quarterly Journal of Economics 112. $443-477$.

Lampi E (2006). The personal and general risks of age-related female infertility: Is there an optimistic bias or not? Working Paper in Economics 231. Goteborg University.

Moffitt R (1984). Optimal life-cycle profiles of fertility and labor supply. Research in Population Economics 5. 29-50.

Strotz RH (1956). Myopia and inconsistency in dynamic utility maximization. Review of Economic Studies 23. 165-180.

Thaler RH (1981). Some empirical evidence on dynamic inconsistency. Economics Letters 8. 201-207. 